\title{
Choro: um movimento de transição da música nacional ${ }^{1}$
}

\author{
Choro: a movement of transition of the national music
}

\author{
Luiz Filipe Moreira Pereira ${ }^{2}$; Sílvio Rodrigo de Moura Rocha (Sílvio Ramiro) ${ }^{3}$
}

\begin{abstract}
RESUMO
Este trabalho apresenta o resultado de cerca de sete meses de uma pesquisa bibliográfica e discográfica do que, segundo Paula Veneziano (2013), "foi a primeira música urbana tipicamente brasileira". Nesse contexto, este artigo tem como objetivo não apenas confirmar essa premissa de o choro ser considerado um representante urbano da música durante o Romantismo e o Realismo, mas também o objetivo de gerar mais conteúdo científico sobre um dos movimentos culturais mais importantes do Brasil, apesar de ainda existir uma quantidade escassa de estudos e materiais de pesquisa sobre esse gênero musical. Com isso em mente, procura-se explicar o choro conforme suas origens e formação, e introduzir alguns conceitos teóricos básicos para que possamos, por último, fazer a análise, por comparação, de choros tradicionais, a fim de comprovar a tese.
\end{abstract}

Palavras-chave: Choro; Realismo; Romantismo.

\begin{abstract}
This work presents the result of about seven months of a bibliographic and discographic research about "choro", which "was the first typically Brazilian urban music", according to Paula Veneziano (2013). In this context, this article aims to contribute to the argument that "choro" can be considered an urban representative of music during the two periods of Brazilian literature: Romanticism and Realism. Also, considering there is a lack of studies and research materials about this musical genre, it aims at contributing to produce more scientific content about one of the most important Brazilian cultural and musical movements. Therefore, we try to explain "choro" according to its origins and formation, introduce some basic theoretical concepts and, finally, conduct the analysis of traditional songs of this musical genre, in order to prove our hypothesis.
\end{abstract}

Keywords: Choro; Realism; Romanticism.

\section{INTRODUÇÃO}

\footnotetext{
${ }^{1}$ Trabalho aprovado e apresentado na Semana de Integração Acadêmica de 2020, da Universidade Federal de Minas Gerais, na modalidade Iniciação Científica Jr.

${ }^{2}$ Estudante do Ensino Médio-Técnico da Central de Ensino e Desenvolvimento Agrário de Florestal (CEDAF), da Universidade Federal de Viçosa - campus Florestal. Pesquisador voluntário de Iniciação Científica Jr., no ano de 2020. Email: luizmope@gmail.com

${ }^{3}$ Professor da Universidade Federal de Viçosa - campus Florestal. Doutor em Literaturas de Língua Portuguesa pela Pontifícia Universidade Católica de Minas Gerais. E-mail: silviorocha@ufv.br
} 
Este artigo surgiu da junção de dois momentos muito específicos no ano letivo de 2020: i) devido ao fato de o conteúdo lecionado nas aulas de Literatura, no Ensino Médio, estar abordando o Realismo no Brasil; ii) devido, ainda, a um dos seus autores, pesquisador de iniciação científica, estar há poucos dias de uma apresentação musical do clássico "Carinhoso", de Ary Barroso. Sendo assim, idealizou-se a execução desta pesquisa voluntária de Iniciação Científica, que une dois temas com imensa importância para a cultura nacional: a literatura e a música popular brasileira.

Com isso em mente, é preciso, primeiramente, ir ao encontro dos fatos sobre esses temas. É notório que o Brasil tem uma das mais ricas culturas no que tange aos movimentos artísticos resultantes da miscigenação das três principais matrizes étnicas que compõem nossa nação. Tal miscigenação resultou em várias peculiaridades em relação aos gêneros clássicos provindos da concepção europeia, podendo ser muito sutis em alguns casos, como em nosso período barroco e romântico, como também muito grandiosos (porém, pouco estudados), sendo um exemplo nosso período realista, o que gera uma lacuna histórica em certas áreas.

Podemos ver, como resultado dessas drásticas mutações, a ausência de um representante na área musical para duas das maiores escolas literárias do Brasil, o Realismo e o Romantismo, devido à falta de estudos profundos sobre a música desse período, como Weffort (2002) afirmam:

A bibliografia disponível sobre o choro apresenta um traço recorrente: constituem representações da memória sobre o seu objeto. Os dados historiográficos acessíveis são regra geral escassos, havendo grande profusão de textos de opinião sobre o choro, mas que não são baseados em fontes primárias. (WEFFORT, 2002, p. 10).

Assim, para se conseguir elaborar uma pesquisa como essa, é necessário fazer uma comparação entre as características dessas escolas e as dos estilos musicais presentes no Brasil por meio de fontes primárias e fontes secundárias para se determinar com quais escolas artísticoliterárias brasileiras o choro poderia se relacionar.

\section{ANÁLISE HISTÓRICA E SOCIAL DO CHORO}

\section{AS ORIGENS DO CHORO}

Devido ao extenso período de colonização de quase 200 anos, a música genuinamente brasileira sempre foi muito dispersa e, nos primeiros tempos, sem compositores registrados. Segundo Waldenyr Caldas (2010), nesse tempo, "vivíamos a plenitude da colonização portuguesa e a música popular brasileira, claro, simplesmente não existia. Os cantos e estilos esparsos (...) ainda não possuíam uma unidade que pudesse caracterizar o mínimo possível da canção colonial brasileira" (CALDAS, 2010, p. 02). Embora houvesse, sim, música produzida por portugueses, 
indígenas e escravos africanos nas terras colonizadas, não havia qualquer integração entre elas, dada a distância entre as áreas administradas pelos portugueses, bem como o nomadismo dos povos indígenas, além da falta de personalidade jurídica e de espaço para que os negros pudessem cultivar e mesmo propagar seu rico universo musical (CALDAS, 2010).

Assim, uma primeira exceção a esse cenário de não integração, somado à falta de registro em notação musical da canção popular brasileira, se dá a partir de 1770, com a presença de Domingos Caldas Barbosa, que representou a modinha "brasileira" para a corte de D. Maria I, gerando um reboliço na corte portuguesa, conforme afirmado por Jairo Severiano, no livro "Uma breve história da música popular brasileira”:

A presença de tão pitoresca figura, um mestiço da colônia que apresentava um tipo de canção diferente de tudo o que se conhecia naquele meio, causou forte impacto e a consagração do cantor, principalmente por parte das damas, sempre cortejadas, às vezes até de forma atrevida, nos improvisos do brasileiro. (SEVERIANO, 2008, p.14).

Com isso, é visível que a música "brasileira" passa a apresentar, quando integra elementos da arte europeia às outras etnias que formavam a nação, uma desenvoltura em relação ao "gingado" e à improvisação característicos da música do mundo antigo. Todavia, esse gênero, a modinha, não tinha representatividade e respeito tão grande como os estilos europeus do mesmo período, levando a comentários de indignação para com essa pitoresca figura por parte da aristocracia portuguesa, sendo um exemplo claro disso o comentário feito por Antônio Ribeiro dos Santos, o qual afirma:

Eu não conheço um poeta mais prejudicial à educação [...] do que este trovador de Vênus e Cupido: a tafularia do amor, a meiguice do Brasil, em geral a moleza americana, que faz o caráter das suas trovas, respira os ares voluptuosos de Pafus e Cítara, e encantam com venenosos filtros a fantasia dos moços e o coração das damas. (SANTOS apud SEVERIANO, 2008, p. 14-15).

Nesse contexto, há uma adaptação da modinha às convenções socioculturais, levando-a novamente aos salões, mas agora renomeada de modinha-canção, o que é ressaltado por Afonso Rui (1954), conforme quem os trovadores da época "compunham dois agrupamentos distintos e inconfundíveis, apartados pelas convenções sociais e pelo exigente formalismo da época: cancioneiros a quem se abriam os salões em brilhantes saraus e seresteiros a quem, ostensivamente, fechavam-se as portas" (RUI, 1954, p. 11). No fundo, apesar da diferenciação marcada pela adaptação do gênero aos salões, a partir de sua tessitura musical, cancioneiros e seresteiros, apesar da estratificação social e da adaptação musical, "eram todos boêmios (...), por índole e por sentimento" (RUI, 1954, p. 11). 
Dessa forma, seguiu-se a representação da música brasileira, quase que em inércia até o ano de 1808, quando as guerras napoleônicas chegaram à península ibérica desencadeando uma fuga da família real portuguesa para o Brasil (elevado a Reino Unido de Portugal, Brasil e Algarves). Nessa fuga, cerca de 15.000 pessoas vieram junto de D. João VI para o Rio de Janeiro, a nova capital do império português. Assim, na tentativa de garantir uma vivência mais cômoda para a corte, foram trazidos ao Brasil inúmeros pertences do acervo da coroa, como documentos, obras de artes, mais de 60.000 livros da biblioteca real e os instrumentos que revolucionariam a música produzida no país, os primeiros pianos. Esses instrumentos foram descritos pelo Visconde de Taunay como de fabricação inglesa pela empresa Broadwood (provavelmente modelos de seis oitavas).

Com a chegada desse novo instrumento e a criação de uma nova vida urbana no Rio, os gêneros europeus (minueto, gavota, valsa, quadrilha e, mais tarde, a polca e o tango), que foram importados pela coroa, começaram a se unir a outros já presentes no Brasil, como o lundu e a modinha, que já era conhecida em Portugal graças a Caldas Barbosa. Essa mistura demorou alguns anos para se concretizar devido a uma relutância, antes referida, à junção dos gêneros e a vários períodos de sobreposições entre eles, sendo esses embates incentivados pela concorrência de casas de teatro do Rio. Tal mistura foi se desenvolvendo ao longo dos anos de 1808 a 1844, ano importante porque, nele, a polca chega ao Brasil, sendo aí registrado o nascimento da "avó" do choro brasileiro, bem caracterizada pelo seu tempo binário, de origem camponesa e muito viva.

Dessa forma, segundo Jairo Severiano (2008), os compositores brasileiros foram evoluindo, incorporando os gêneros europeus ao batuque, resultando no tango brasileiro, no maxixe e no choro, este último considerado o mais importante gênero musical instrumental brasileiro, tendo forte influência da polca em sua formação, tanto que, até a década de 1910, os choros eram chamados de polca. Esses fatos levaram Jairo Severiano a considerar nossos choros primitivos como: "Polcas tocadas à moda brasileira, ou seja, polcas que incorporavam a síncope do batuque" (SEVERIANO, 2008, p. 34). Com o decorrer do tempo, principalmente pelas mãos de Joaquim Antônio da Silva Calado (1848-1880), e mesmo com o constante abrasileiramento, o choro começou a ganhar as classes altas da sociedade carioca do final do século XIX, assim ganhando status por meio de figuras como Ernesto Nazareth (1863-1934), Chiquinha Gonzaga (1847-1935) e, futuramente, na primeira metade do século XX, com as gravações de choro na Casa Edison, por meio da Banda do Corpo de Bombeiros (que foi essencial para a propagação do choro pelo país), chegando ao seu ápice com Alfredo da Rocha Viana ou, como é mais conhecido, Pixinguinha. 
Após explanar sobre a origem do choro, tanto em sua ramificação linguística quanto histórica, é relevante analisar o que podemos definir como os "4 grandes". Esse é um grupo seleto de compositores que influenciaram o choro em todas as suas áreas, composto por Joaquim Calado, Ernesto Nazareth, Chiquinha Gonzaga e Pixinguinha.

Dessa forma, começaremos por Joaquim Calado. Calado pode ser considerado uma das figuras de maior importância para a formação do choro e por seu estilo romântico no país. Como postulado por Jairo Severiano, o fato de ter o pai músico, juntamente com o grande interesse demonstrado pelos gêneros populares da música brasileira, foram essenciais para o início de sua carreira, bastando-lhe apenas a entrada no meio acadêmico para consagrar seu nome; sendo um exímio flautista, tornou-se professor do Imperial Conservatório de Música, inaugurando o que é considerado como a formação clássica do choro - ou como era chamada: "Choro do Calado". Tal formação é composta por um instrumento solista (geralmente uma flauta), dois violões e um cavaquinho. Calado também produziu várias obras durante sua vida, sendo "Flor amorosa" a mais reconhecida.

Seguindo alguns anos, após Calado, temos o grande pianista Ernesto Nazareth. Vindo de uma família modesta do Rio de Janeiro, nos primeiros anos de produção de suas mais de 220 obras, vemos a predominância de polcas, as quais, em parte, foram substituídas pelo tango. Outra importante característica dentro de suas obras, que é um consenso entre os estudiosos e torna-se seu diferencial, consagrando-o como um ícone da música brasileira do século XIX, é o fato de ter conseguido colocar a "alma" do choro em suas composições com uma grande virtuosidade, já que que elas fazem uso de uma dualidade de espaço e ocasião, como dito por Jairo Severiano:

Um tango, como o" Brejeiro", por exemplo, se executado ao piano como o autor o escreveu, é uma peça refinada, digna de qualquer sala de concerto. Se, entretanto, é interpretada por um músico popular, passa a ser uma composição chorística autêntica, retornando às origens. (SEVERIANO, 2008, p. 28).

Mantendo-se no mesmo período, é válido ressaltar uma contemporânea de Nazareth que, em sua própria biografia online (DINIZ, 2011), pode ser colocada como uma das grandes compositoras da música popular brasileira e dona de um temperamento no mínimo exaltado. Esta era Chiquinha Gonzaga, mãe de 4 filhos e compositora, que teve uma vida marcada por lutas para adentrar no meio musical devido ao fato de ser mulher (mesmo sendo "protegida" por figuras de peso, como o próprio Calado). Pode-se dizer que suas composições refletem sua personalidade forte e decidida e sem se romantizar na sociedade da época.

Por fim, temos o ápice do choro em todas as suas áreas com um flautista carioca chamado Alfredo da Rocha Viana Filho - mais conhecido como Pixinguinha. Nascido no Rio em uma casa 
de músicos, Pixinguinha sempre teve contato com a música popular desde novo, fato somado a seu excelente ouvido e que possibilitou começar sua carreira aos 14 anos, tendo dois momentos principais para seu sucesso. Primeiramente, no ano de 1911, com a gravação do seu primeiro disco, em que seu talento já era visto de forma nítida, como apontado por Henrique Cazes, em seu livro "Choro: do quintal ao Municipal", no qual afirma:

O sopro da flauta de Pixinguinha [...] não se parecia nem um pouco com o dos flautistas acadêmicos da época. Era muito mais rítmico, sem vibrato, e conforme nos explica a tese Flautistas populares brasileiros, de Andréa Ernest Dias, um som gerado com muito ar, em golpes enérgicos. (CAZES apud SEVERIANO, 2008, p. $83)$.

Depois, em 1919, com a criação dos Batutas, esse grupo passa a ser composto por nove instrumentistas que levaram a música popular brasileira em suas turnês pela França e pela Argentina. Com o fim do grupo e o início das gravações eletromagnéticas, Alfredo começa a gravar vários sucessos e a lançar composições de sua autoria até 1929, quando foi chamado para dirigir a Orquestra Victor Brasileira. Com esses trabalhos, Pixinguinha renovou a música brasileira e o choro, levando-o a outro patamar e dando reconhecimento mundial à nossa música.

\section{O LADO SOCIOLITERÁRIO DO CHORO}

Com a origem historiográfica do choro e seus grandes compositores revisada, vamos ao encontro do proposto para este artigo: a busca de uma escola artístico-literária com a qual o choro se relacione. A princípio, decidimos analisar a própria formação etimológica da palavra choro, o que nos dará um norte, para, então, começarmos um exame mais verticalizado.

Com isso, chegamos a várias divergências acadêmicas sobre a ascendência dessa pequena palavra, entretanto operamos com duas possíveis ideias. A primeira, vinda do Maestro Batista Siqueira, que nos traz a informação de que o termo "choro" surgiu da colisão linguística entre duas palavras, os verbos "chorar" e chorus ("coro" em latim); e a outra, provinda de José Ramos Tinhorão, que atribui a origem do termo à sensação de melancolia transmitida pelas modulações improvisadas de contracanto do violão, por meio das cordas com frequências graves do instrumento (também chamadas de "baixarias"). Assim, podemos inferir que, mesmo com ideias diferentes sobre a origem da palavra, ambas levam, em sua síntese, ao objetivo de retratar uma música mais lenta e com construções harmônicas e melódicas melancólicas.

Mantendo essa ideia de melancolia, podemos começar a ligar os pontos para a confirmação de nossa tese. De fato, o primeiro movimento que vem à mente ao pensar em um gênero brasileiro 
do século XIX que demonstra melancolia seria o Romantismo. Porém, como essa escola literária ocorreu nos primórdios do choro, buscamos as interpretações de um compositor desse período e nada melhor do que o fundador do choro, Joaquim Calado, para nos mostrar essa correlação. No seu choro "Flor Amorosa" (1880), mesmo estando cerca de 20 anos atrasado em relação ao auge da segunda geração romântica, Calado retrata claramente, em sua letra, as características do amor impossível e da idealização de uma donzela. Entretanto, já há, nesse choro, algumas pequenas aparições do Realismo, com uma certa "guerra" aparente entre os dois movimentos, devido ao fato de o eu lírico lutar entre duas personalidades, a de um cavalheiro que quer conquistar sua dama perfeita e a de um homem que tem em mente os prazeres do beijo e retira a dama do altar. Tais afirmações são confirmadas em todo o decorrer da canção, que será analisada mais adiante neste artigo.

Sabendo agora da ligação do choro com o Romantismo, podemos tecer a relação entre o choro e o Realismo. Tal ideia pode ser comprovada por meio de várias composições de artistas que deram sequência ao choro depois de Calado, principalmente nas letras de suas canções, que, mesmo sendo escritas posteriormente, demonstram uma evidente relação com o Realismo, como as escritas por Ernesto Nazareth e Chiquinha Gonzaga. A princípio, iremos analisar Nazareth em suas músicas “Odeon” (1910) - com letra posterior de Vinícius de Moraes -, a qual, mesmo sendo conhecida como tango brasileiro, cita diretamente o choro em sua letra - e "Apanhei-te, cavaquinho", a qual mostra o "bom malandro", representado por um cavaquinho.

Em ambas as canções, são visíveis as características do Realismo, por exemplo, na representação do malandro no choro como um cavaquinho, já que ambos são característicos da população pobre do Rio e que era considerada sem valor cultural para a época, como se pode ver no conto escrito por Machado de Assis, contemporâneo de Ernesto Nazareth, "Um Homem Célebre" (1883), em que o personagem principal, Pestana, vive com a ideia de criar uma música que remonte aos grandes clássicos. Entretanto, esse protagonista somente consegue criar polcas, afirmando que a polca era um estilo de "música fácil", ou seja, tratando a polca como estilo/ritmo de baixo nível e sem relevância para a alta sociedade da época.

$\mathrm{Na}$ música "Odeon", letrada posteriormente por Vinícius de Moraes com uma nítida verossimilhança com o contexto social da época em que foi composta, no fim do século XIX, podemos ver o que pode ser considerado uma homenagem ao choro e a seus tempos de glória, ressaltando as suas características, como nas partes:

Terçando flauta e cavaquinho

meu chorinho se desata.

Tira da canção do violão

esse bordão 
que me dá vida

e que me mata.

É só carinho

o meu chorinho

quando pega e chega

assim devagarzinho

meia-luz, meia-voz, meio-tom

meu chorinho chamado Odeon.

(NAZARETH; MORAES, 1968).

Ao mesmo tempo, a letra da canção mostra uma pessoa que, visivelmente, trata o choro como uma manifestação sincera, por meio da alegria que está tipicamente associada à música popular dos subúrbios.

Por fim, vale ressaltar Chiquinha Gonzaga, que, tanto em sua vida profissional como compositora quanto em sua vida pessoal, retrata bem os padrões realistas da mulher, assim desconstruindo a imagem romântica. Isso é visível em canções como "Atraente" ou "Corta-Jaca", que, mesmo sendo um maxixe, ainda traz bastante da personalidade de Chiquinha, além de fazer uma crítica ao episódio conhecido como "A noite do corta jaca".

\section{ANÁLISE TEÓRICA DAS PARTITURAS E LETRAS DO CHORO}

\section{ANÁLISE DAS PARTITURAS E SUAS MELODIAS}

Diante das informações trazidas anteriormente, surge a necessidade de confirmações tanto no âmbito da teoria musical, por meio das partituras, quanto na teoria literária, por meio das letras das músicas. Com isso em mente, analisaremos duas partituras de choro compostas por Ernesto Nazareth ("Odeon" e "Beija-Flor") e duas partituras de polcas europeias, produzidas no período romântico por Johann Strauss.Jr (“Amazonen-Polka, Op.9” e "Bürger-Ball-Polka”).

Comecemos, então, com “Odeon”, de Ernesto Nazareth, que apresenta várias similaridades com a composição "Bürger-Ball-Polka", de Strauss, em relação às suas células rítmicas, como podemos ver nas partituras a seguir: 


\section{Exemplo 1- "Odeon"}
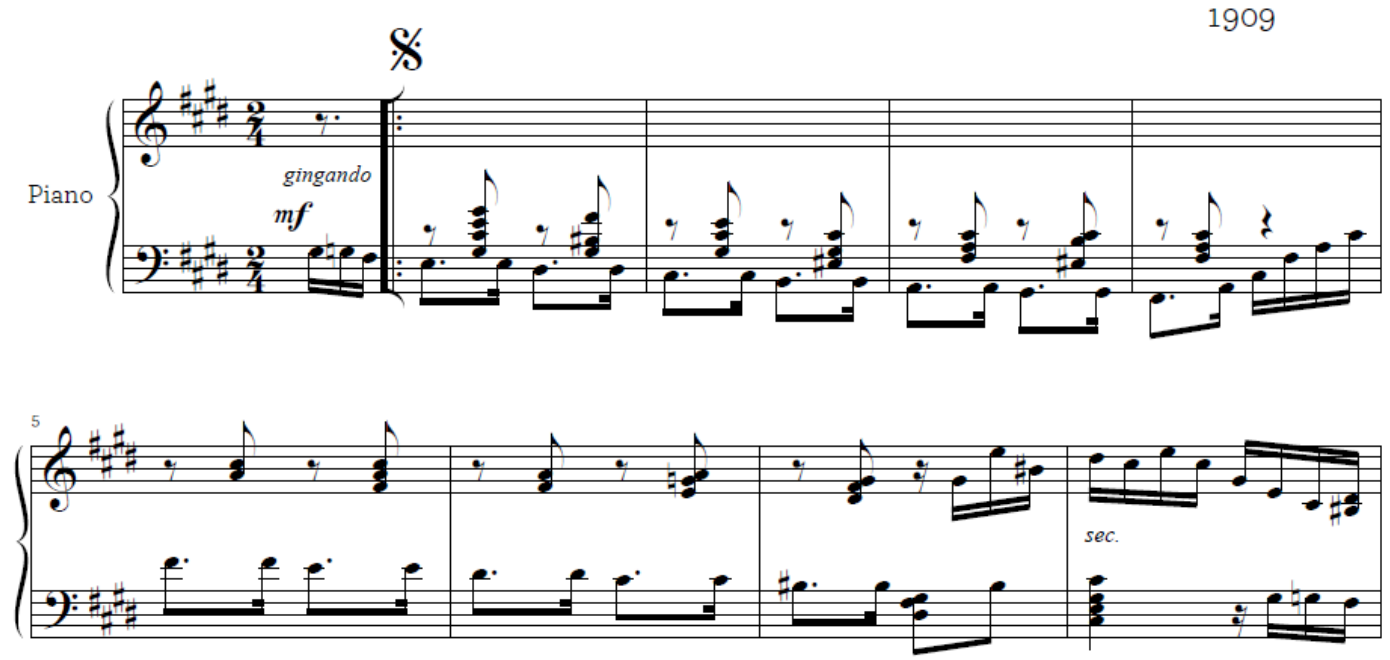

Fonte: Ernesto Nazareth,1909.

Na parte mostrada acima, temos os oito compassos iniciais de "Odeon", em que é evidente a presença das baixarias sendo executadas pela mão esquerda no piano, tendo como célula rítmica constante o conjunto colcheia pontuada e semicolcheia e, entre essas, um acorde servindo de contraponto. Tal ideia se repete durante toda a música, gerando, assim, o que pode se chamar de ritmo do choro, sendo tal ritmo visível também em várias polcas europeias como demonstrado no trecho abaixo de "Bürger-Ball-Polka". 4

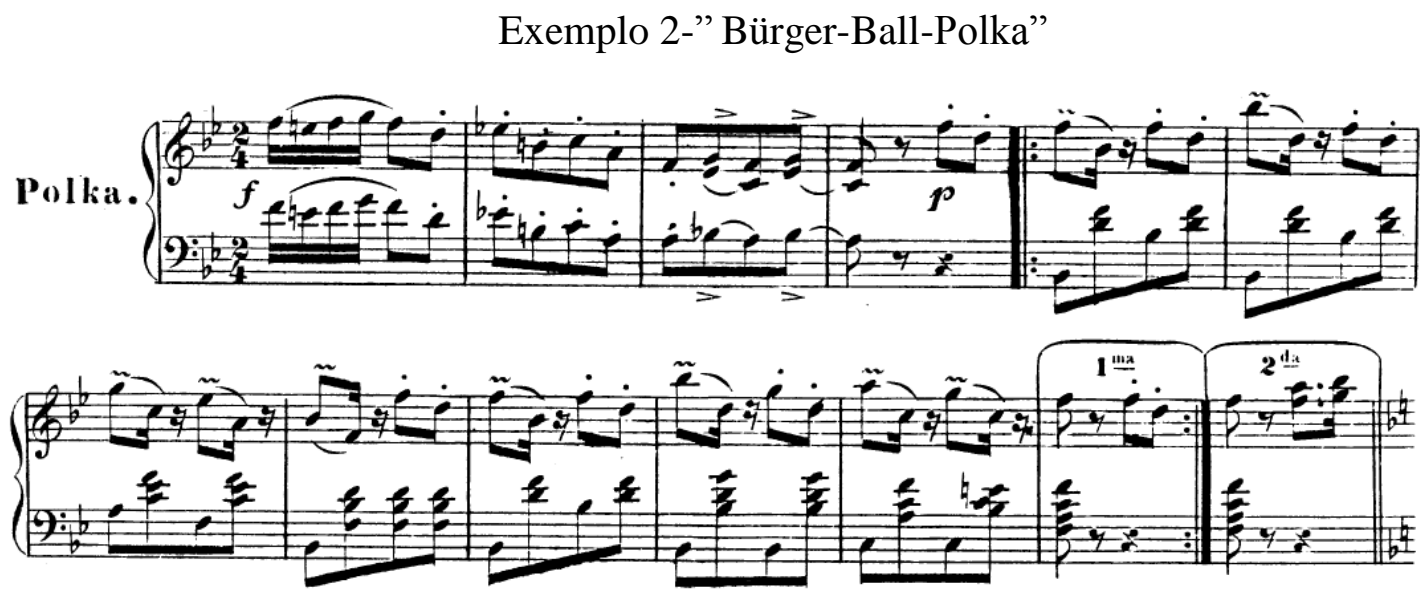

Fonte: Johann Strauss Jr, 1854.

\footnotetext{
${ }^{4}$ Para o leitor leigo em interpretação de partituras, recomenda-se ouvir "Odeon" e "Bürger-Ball-Polka", nos respectivos links: https://www.youtube.com/watch?v=UWtmW7tejrI\&ab_channel=PaulBarton e https://www.youtube.com/watch? $\mathrm{v}=898 \mathrm{cSqUNWj} 4 \& \mathrm{ab} \_\mathrm{channel}=$ SlovakPhilharmonic-Topic
} 
A partir de uma análise à primeira vista, já é visível a semelhança na questão da fórmula de compasso, por ambas as músicas serem binárias e pelo fato de serem parecidas em suas melodias. De tal forma, é valido fazer uma observação mais profunda das fórmulas de compasso, em que é possível se observar uma variação em relação à música "Odeon”, que deve ser considerada como o "fator diferenciador" dos dois gêneros (nesse caso, a ausência do ponto de aumento na colcheia). Entretanto, tal fator não nos inibe de ver a clara relação entre ambas as partituras, devido às células rítmicas seguirem o padrão de colcheia seguida de uma semicolcheia.

Como segunda análise, escolhemos a Polca "Amazonen-Polka", de Johann Strauss, como parâmetro de comparação com a música "Beija-Flor", de Ernesto Nazareth, em que podemos identificar uma relação não tão evidente quanto a já citada acima. Assim, é interessante executar uma análise mais detalhada de tais peças para que possamos visualizar as semelhanças presentes em ambas as composições. Começaremos, então, por um trecho de música "Amazonen-Polka":

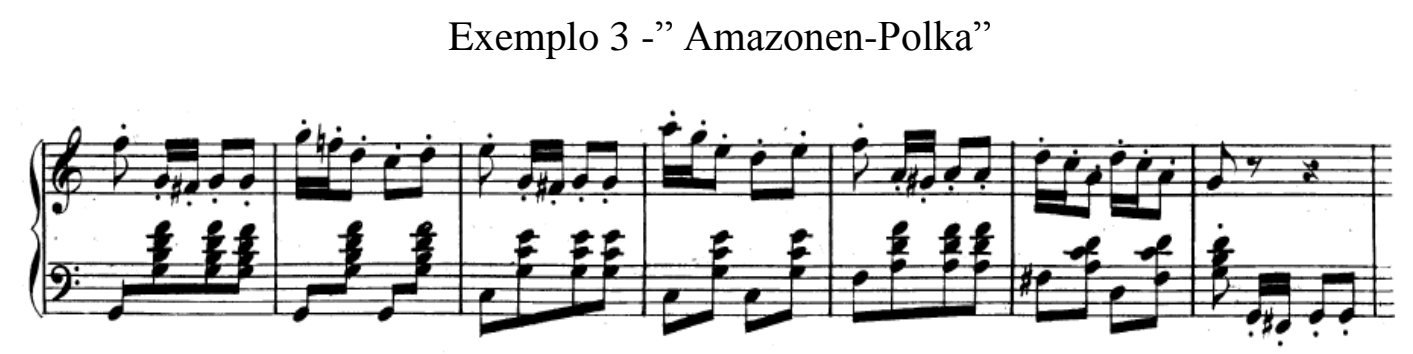

Fonte: Johann Strauss Jr, 1846.

Nessa parte, sabemos, já de antemão, que a música tem como fórmula de compasso a estrutura binária. Assim podemos nos ater a uma nova célula de compasso que surge baseada na utilização de três colcheias e de duas semicolcheias, sendo que essas podem se encontrar em duas sequências: a primeira, é composta por uma colcheia pontuada seguida de duas semicolcheias e, por fim, de duas colcheias; a segunda, é composta de duas semicolcheias seguidas de outras três colcheias, sendo todas em staccato, o que é repetido várias vezes dentro da composição. Tal sequência também pode ser vista na música "Beija- Flor", a partir do compasso trinta e seis, com um arranjo um pouco diferente do de Strauss, mas que, musical e visualmente, ainda mantém semelhanças. 


\section{Exemplo 4 - "Beija- Flor"}

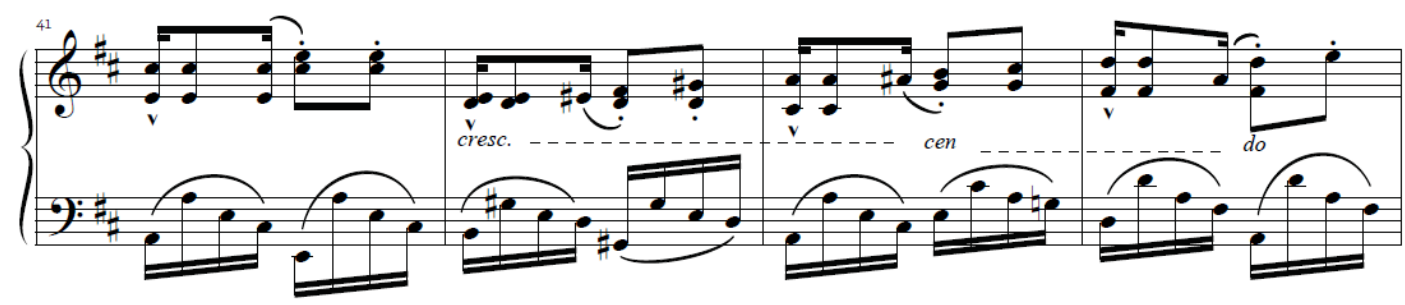

Fonte: Ernesto Nazareth, 1884

Por meio do trecho mostrado acima, pertencente à música "Beija-Flor", que tem fórmula de compasso binaria, igual em amazonen-Polka, podemos ver, em todos os 4 compassos, a presença de três colcheias e duas semicolcheias que aparecem com o seguinte arranjo: semicolcheia, colcheia, semicolcheia seguida de duas colcheias com staccato. Com isso, podemos ver que existem uma grande semelhança entre ambas as músicas (devido ao fato de terem as mesmas figuras musicais em sua estrutura) que prova sua correlação. Porém, é possível observar que existem diferenças, em relação às fórmulas de "Amazonen-Polka", no arranjo da estrutura de duas semicolcheias seguidas de colcheia para uma colcheia entre duas semicolcheias. Tal rearranjo demonstra que existe uma relação quase de maternidade entre as duas composições, tornando-as, ao mesmo tempo, similares e diferentes em certos aspectos sonoros.

\section{ANÁLISE DAS LETRAS}

Outra forma, aliada à análise das partituras, de reafirmar as teorias propostas na primeira parte deste artigo é a execução de uma análise das letras originais dos choros ou daquelas feitas posteriormente. Vale-se a ressalva de que, mesmo sendo feitas em um período diferente do de produção da música original, as letras analisadas trazem verossimilhança com o período da composição original. Dessa forma, escolhemos para análise quatro músicas letradas: "Odeon”, letrada por Vinícius de Moraes”; “Apanhei-te Cavaquinho”, por Baldomán (possível pseudônimo de Hubaldo Maurício); "Flor Amorosa”, por Catulo da Paixão Cearense; e "Atraente”, por Hermínio Bello de Carvalho.

Comecemos, então, pelas duas músicas de Ernesto Nazareth, "Odeon" e "Apanhei-te Cavaquinho", ambas letradas somente depois de sua publicação, mas levando em suas letras uma extensa bagagem de significado relacionado à época original. 


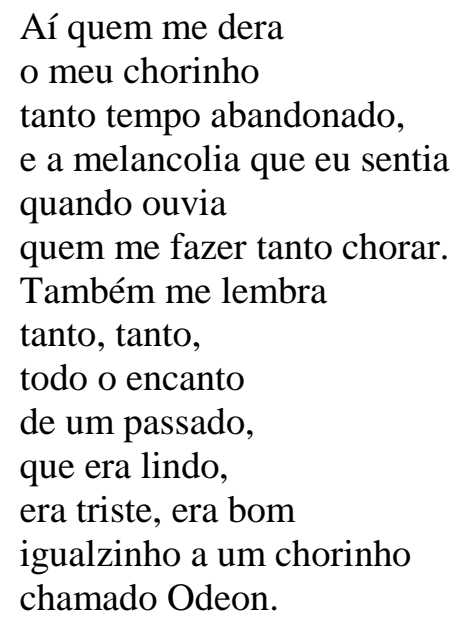

(NAZARETH; MORAES, 1968).

No trecho acima, temos a primeira parte da letra de "Odeon", em que é visível o início da presença de uma melancolia em relação a um amor distante, que passa a circundar a música até seu fim, evidenciando uma relação com o Romantismo. Isso é comprovado por meio das falas do eu lírico na primeira estrofe, na qual ele relembra um passado com melancolia (representado, comparativamente, por um choro). É possível reafirmar essa mesma interpretação na terceira parte, pois o eu lírico indica que ainda persegue a ilusão do amor verdadeiro e de outros sentimentos possivelmente puros, voltando ao passado, lembrando de sua infância ${ }^{5}$ e de seus antigos sentimentos.

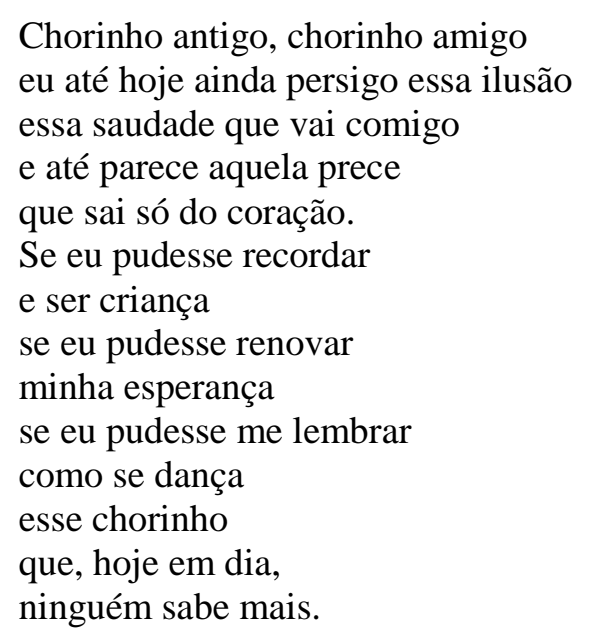

(NAZARETH; MORAES, 1968).

Seguindo as análises, escolhemos a letra de "Apanhei-te Cavaquinho", pois retrata uma das principais ideias presente no Realismo, a ideia de representar o indivíduo real sem idealizações, o que, no caso do Brasil, desenvolveu-se a partir da imagem do "malandro". Tal ideário de formação

\footnotetext{
${ }^{5}$ Esse tipo de sentimento saudosista é uma característica fundadora do ideal romântico do século XIX no Brasil, representado, por exemplo, no clássico poema "Meus oitos anos", de Casimiro de Abreu: "Oh! que saudades que tenho / Da aurora da minha vida, / Da minha infância querida / Que os anos não trazem mais!” (ABREU, 2004).
} 
do "malandro" já é presente na arte brasileira desde o livro Manuel Antônio de Almeida, "Memórias de um Sargento de Milícias" (que, embora seja um livro escrito no Romantismo, já antecipa traços da incipiente estética Realista). Assim, vemos, evidentemente, as características de um malandro na composição de Baldomán, na primeira parte, fazendo uma descrição de um cavaquinho, um instrumento popular que está presente nas ruas e nas rodas de música, acarretando desprestígio e mostrando uma clara relação com o malandro brasileiro.

Um cavaquinho, cabecinha pequenina, no formato dum oitinho,

De boquinha redondinha, de pescoço compridinho, orelhinha

De madeira o terninho, gravatinha de cordinha, falou:

[cravelhinha,

Sou miudinho, tenho quatro "cordazinha", mas dou vida ao chorinho,

Sou o molho da sambinha! "Seu" pandeiro, cuidadinho!...

Tome tento, ó flautinha!... "Seu" piano, diga ao pinho: cavaquinho já [chegou!

(CALADO; BALDOMÁN, 1940).

Nesse trecho, o modo selecionado pelo eu lírico para se referir ao cavaquinho evoca, nitidamente, a inserção popular do instrumento na sociedade, por meio de diminutivos (ao mesmo tempo irônicos e afetivos), de termos sem concordância ("quatro "cordazinha"”), além do tom malandro ao dialogar com os outros instrumentos ("Seu' pandeiro" / “'Seu' piano"”) e se impor no cenário (“cavaquinho já chegou”).

Por fim, temos as letras de "Flor amorosa" e "Atraente", sendo uma o oposto da outra em relação aos seus períodos, já que a primeira é uma clara representação do Romantismo, e a segunda, uma representação do Realismo. As afirmações sobre "Flor Amorosa" podem ser vistas e confirmadas em todo o decorrer da letra, pois ela segue persegue a criação de uma "dama perfeita", descrevendo todas as suas características e comparando-a com uma flor. Outro ponto a se ressaltar é a ideia da conquista do beijo da "flor" que o eu lírico busca e ainda insinua como um sonho, ou seja, um objetivo inalcançável, idealização bem característica do Romantismo. Tais interpretações podem se confirmar pelas estrofes a seguir:

Flor amorosa, compassiva, sensitiva, vem porque

É uma rosa orgulhosa, presunçosa, tão vaidosa

Pois olha a rosa tem prazer em ser beijada, é flor, é flor

Oh, dei-te um beijo, mas perdoa, foi à toa, meu amor

Em uma taça perfumada de coral

Um beijo dar não vejo mal

É um sinal de que por ti me apaixonei 
Talvez em sonhos foi que te beijei

Se tu pudesses extirpar dos lábios meus

Um beijo teu tira-o por Deus

Vê se me arrancas esse odor de resedá

(CALADO; CEARENSE, s/d).

Por conseguinte, a letra de "Atraente" prova ser oposta a "Flor Amorosa", sendo assim muito mais próxima do Realismo na descrição da mulher. Tal fato é confirmado pelo decorrer da composição, em que é descrito o andar de uma mulher, com uma ideia de desconstruir a ideia de uma donzela indefesa e perfeita, chamando-a de atrevida e de esmagadora de corações. Outro ponto que reforça tal afirmação pode ser encontrado mais à frente na canção, com o eu lírico adicionando novas características à personagem feminina, como" falsa", "danada"," perigosa"," indecorosa" e" rancorosa", mostrando o que seria o avesso da idealização da mulher, uma característica já relevante no Realismo.

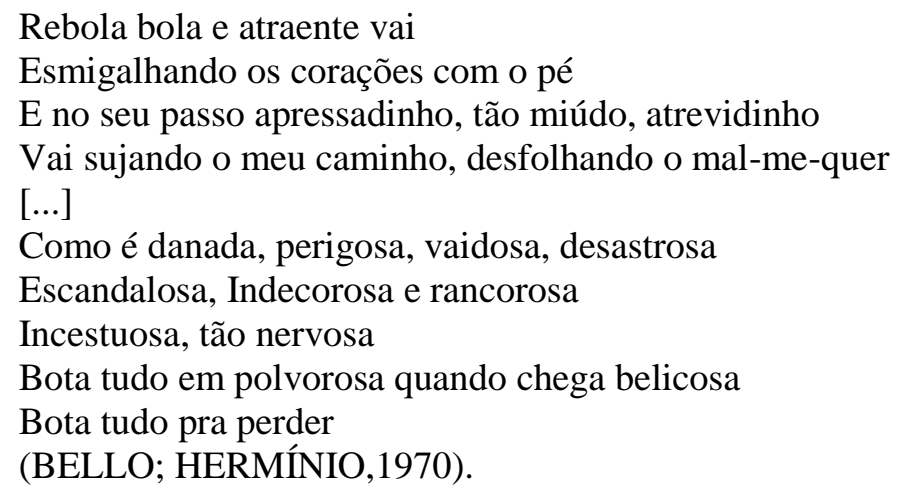

\section{CONCLUSÃO}

Com todos os argumentos postos, primeiramente em relação à historiografia e à discografia do choro (que demonstram sua importância para o ideário nacional de fusão de etnias), seguido por suas características sócio literárias (as quais apresentaram, por meio das letras, a relação do choro com as escolas literárias da época), além da análise de letras de choros e comparação de partituras de polcas europeias com choros brasileiros, podemos concluir que o choro tem seu cerne nos ideias de ambas as escolas literárias (Romantismo e Realismo) vigentes em sua época de criação. Com isso, a formação do choro ajudou a consolidar a criação de uma música genuinamente brasileira, integrada aos valores da época, além de permitir sua exportação para o mundo, por causa da referência musical europeia fundida à brasileira, sendo assim um gênero de transição de períodos de nossa historiografia lítero-musical. 


\section{REFERÊNCIAS}

ABREU, Casimiro de. As Primaveras. São Paulo: Ática, 2004.

ALMEIDA, Manuel Antônio de. Memórias de um sargento de milícias. São Paulo: Moderna, 2015.

CECATO, Lica. Apanhei-te, cavaquinho. 2016. Disponível em: https://www.youtube.com/ watch?v=hYils_jKNII\&ab_channel=UMCAF\%C3\%89L\%C3\%81EMCASA. Acesso em: 15 set. 2020 .

CONDÉ, Lysia. FLOR AMOROSA (Joaquim Callado e Catullo da Paixão Cearense) por Lysia Condé. Natal, 2014. Disponível em: https://www.youtube.com/watch?v=xwg CUWnhD8\&ab_channel=LysiaCond\%C3\%A9. Acesso em: 15 set. 2020.

CALDAS, Waldenyr. Iniciação à música popular brasileira. Barueri, São Paulo: Manole, 2010.

DINIZ, Edinha. Chiquinha Gonzaga: uma história de vida. 2011. Disponível em: https://chiquinhagonzaga.com/wp/biografia/. Acesso em: 19 fev. 2021.

GONZAGA, Chiquinha. Atraente. Disponível em: https://immub.org/compositor/herminio-bellode-carvalho. Acesso em: 08 set. 2020.

NAZARETH, Ernesto; MAURÍCIO, Hubaldo. Apanhei-te cavaquinho. Rio de Janeiro Disponível em: https://www.ernestonazareth150anos.com.br/works/view/20. Acesso em 15 set. 2020.

NAZARETH, Ernesto. Beija-flor: tango brasileiro. Rio de Janeiro: Ernesto Augusto de Mattos, 1936. Disponível em: https://ernestonazareth150anos.com.br/works/view/130. Acesso em: 08 set. 2020.

NAZARETH, Ernesto. Odeon: tango brasileiro. Rio de Janeiro: Casa Mozart, 1909. Disponível em: https://www.ernestonazareth150anos.com.br/Works/view/136. Acesso em: 07 set. 2020.

NAZARETH, Ernesto; MORAES, Vinícius. Odeon. Rio de Janeiro. Disponível em: https://www.ernestonazareth150anos.com.br/Works/view/136. Acesso em 10 set. 2020.

NAZARETH, Ernesto. Odeon: tango brasileiro. Rio de Janeiro: Casa Mozart, 1909. Disponível em: https://www.youtube.com/watch?v=UWtmW7tejrI\&ab_channel=PaulBarton. Acesso em: 15 set. 2020.

PIXINGUINHA. ENCICLOPÉDIA Itaú Cultural de Arte e Culturas Brasileiras. São Paulo: Itaú Cultural, 2021. Disponível em: http://enciclopedia.itaucultural.org.br/pessoa12197/pixinguinha. Acesso em: 19 fev. 2021. Verbete da Enciclopédia. ISBN: 978-85-7979-060-7

RUI, Afonso. Boêmios e seresteiros do passado. Salvador: Livraria Progresso Editora, 1954.

SEVERIANO, Jairo. Uma história da música popular brasileira: das origens à modernidade. São Paulo: Editora 34, 2008. 
STRAUSS, Johann. Bürger-Ball-Polka: Op.145. Vienna: Haslinger, n.d. [1854]. Plate C. H. 11,657, 1854. Disponível em: https://imslp.org/wiki/B\%C3\%BCrger-BallPolka\%2C_Op. 145_(Strauss_Jr.\%2C_Johann). Acesso em: 07 set. 2020.

STRAUSS, Johann.BURGERBALL-POLKA, Op. 145. Produção: Slovak Philharmonic, 2018. Disponível em: https://www.youtube.com/watch?v=898cSqUNWj4\&ab_channel=SlovakPhilha rmonic-Topic. Acesso em: 15 set. 2020.

STRAUSS, Johann. Amazonen-Polka: Op.9. Vienna: Pietro Mechetti, n.d.[1846]. Plate P.M. 4066, 1846. 1 partitura. Disponível em: https://imslp.org/wiki/Amazonen-Polka\%2C_Op.9_(Strauss _Jr.\%2C_Johann). Acesso em: 08 set. 2020.

VALENTE, Paula. A improvisação no choro: história e reflexão. DAPesquisa, 2018. Disponível em: https://www.revistas.udesc.br/index.php/dapesquisa/article/view/14092. Acesso em: 22 set. 2020 .

VALENTE, Paula Veneziano. Pixinguinha e o modelo vertical de improvisação do choro brasileiro. In: I SIMPÓSIO BRASILEIRO DE PÓS-GRADUAÇÃO EM MÚSICA. Rio de Janeiro, 2010, p. 489-495. Disponível em: http://www.seer.unirio.br/index.php/simpom/ article/download/2729/2046. Acesso em: 19 set. 2020.

WEFFORT, Alexandre et al. Choro: Expressão Musical Brasileira: caminhos de aproximação ao universo do choro. 2002. Tese (Ciências Musicais) - Conservatório Nacional de Lisboa, Rio de Janeiro, 2002. Disponível em: https://www.academia.edu/15634088/CHORO_EXPRESS\%C3\% 830_MUSICAL_BRASILEIRA. Ac 